\title{
A select issue in the postpartum period: contraception
}

\section{The importance of providing postpartum contraception counseling}

\author{
Whitney Cowman, MD, ${ }^{1}$ Abbey Hardy-Fairbanks, MD, ${ }^{1}$ Jill Endres, MD, ${ }^{2}$ Colleen K. \\ Stockdale, MS, MD ${ }^{1}$
}

Keywords: postpartum, contraception, guidelines, counseling

\begin{abstract}
One half of pregnancies in the United States are unintended and associated with adverse pregnancy outcomes. The postpartum period is an important, yet underutilized, time to initiate contraception. The U.S. Medical Eligibility Criteria for Contraceptive Use, 2010 provides evidence-based guidelines for choosing a contraceptive method and an update in 2011 specifically addresses contraceptive method use in the puerperium. The variety of contraceptive methods include hormonal contraception, lactational amenorrhea, barrier contraception, natural family planning, and sterilization. Ideally, counseling about contraceptive choice should begin early in pregnancy care and continue postpartum; it should also include a variety of teaching modalities. Specifically we recommend LARC options such as intrauterine devices and etonorgestrel implants, postpartum tubal sterilization, and progestin-only pills for those desiring an oral method.

${ }^{1}$ Department of Obstetrics and Gynecology, Carver College of Medicine, University of lowa Hospitals and Clinics, lowa City, IA, 522422

${ }^{2}$ Department of Family Medicine, University of lowa Hospitals and Clinics, lowa City, IA, 52242
\end{abstract}

Data from the United States reveals that of the approximately 6.6 million pregnancies per year, one-half are unintended. ${ }^{1-3}$ Of the approximately 61 million women of reproductive age in 2006-2010, 62\% were using some form of contraception. ${ }^{4} \quad 7.7 \%$ of those not using contraception had intercourse in the previous 3 months, and represent those at highest risk for unintended pregnancy. ${ }^{5}$ Unintended pregnancies are associated with adverse pregnancy outcomes and behaviors, including late entry into prenatal care, decreased breastfeeding, and low birth weight. ${ }^{6}$ Also, short interval pregnancies are at increased risk for obstetric complications, including low birth weight, preterm birth and neonatal mortality. ${ }^{7-9}$ The optimal interval between pregnancies is debated, but greater than 11-18 months has been suggested as reducing complications in the subsequent pregnancy. ${ }^{7,8}$ Postpartum contraception is vital to the reduction of short interval pregnancies, which is a significant source of neonatal

Please cite this paper as: Cowman W, Hardy-Fairbanks A, Endres J. Stockdale CK. A select issue in the postpartum period: contraception. Proc Obstet Gynecol. 2013;3(2):Article 1 [15 p.]. Available from: http://ir.uiowa.edu/pog/. Free full text article.

Corresponding author: Whitney Cowman, Department of Obstetrics and Gynecology, University of lowa, 200 Hawkins Drive, lowa City, IA 42242. whitney-cowman@uiowa.edu

This is an Open Access article distributed under the terms of the Creative Commons Attribution 3.0 Unported License (http://creativecommons.org/licenses/by/3.0), which permits unrestricted use, distribution, and reproduction in any medium, provided the original work is properly cited. 
morbidity and medical care costs.

The immediate puerperium is an important period to initiate contraception. ${ }^{10}$ Women are often motivated to prevent or delay another pregnancy, they have immediate access to health care providers, and they are known not be pregnant. ${ }^{10,11}$ Because ovulation may occur as early as 25 days postpartum among women not breastfeeding, providing an effective contraceptive method during the puerperium is vitally important in reducing unintended pregnancy. ${ }^{12}$

The puerperium is a unique time period in a woman's life, resulting in unique contraception needs. Understanding and communicating the risks and benefits of the various contraceptive methods is vital, as some contraceptive forms are better suited than others for use during this time period.

In 2010, the Centers for Disease Control (CDC) published U.S. Medical Eligibility Criteria for Contraceptive Use, 2010 (US MEC), ${ }^{13}$ providing evidence-based guidelines for choosing a contraceptive method based on the relative safety for women with certain characteristics/conditions, including those who are postpartum. A category 1 distinction indicates that there are no restrictions for the use of a particular contraceptive method. Category 2 designates that the method may be used but that individualization and careful follow-up may be required. Category 3 indicates that a certain method is generally not recommended unless other methods are unavailable or unacceptable. Category 4 notes an unacceptable health risk may be conferred with use. ${ }^{13}$ The CDC-MEC criteria can be used to evaluate options for women in the postpartum period with and without chronic medical conditions. Updates to the CDC-MEC recommendations specific for postpartum women were released in 2011 and will be reviewed here.

\section{Hormonal contraception}

\section{Combined estrogen and progestin hormonal contraceptive agents (oral combined hormonal contraceptive pills, transdermal patch, vaginal ring)}

Hormonal contraceptives are among the most used methods of contraception in the United States. In fact, according to the most recent data from the National Center for Health Statistics, the oral contraceptive pill is used by $17.1 \%$ of all reproductive age women $(28 \%$ of women using some form of contraception), $1.3 \%$ use the contraceptive ring, and $0.9 \%$, the implant or transdermal patch. ${ }^{5}$ These methods prevent ovulation by suppressing hypothalamic gonadotropin-releasing factors, which then prevents pituitary secretion of FSH and LH. Estrogens prevent ovulation by suppressing FSH release, and also stabilize the endometrium. Progestins suppress $\mathrm{LH}$, thicken cervical mucus, and render the endometrium unfavorable for implantation. ${ }^{14}$ Oral progestin-only options can provide contraceptive efficacy, although the estrogen component improves cycle control, unfortunately at the expense of estrogenic side effects such as nausea, breast tenderness and thromboembolic events. $^{15} \quad$ Progestins produce androgenic side effects such as acne, hirsutism and lipid changes. ${ }^{15}$ The overall side effect profile, therefore, is 
dependent upon the concentration of each hormone and specific type of progestin. $^{15}$

Combined hormonal contraceptive pills have many benefits, including familiarity with the method, effectiveness, safety, reversibility, cycle control, decrease in dysmenorrhea, decrease in days of bleeding and amount of blood loss and other, non-contraceptive benefits. ${ }^{16}$ Non-oral delivery methods such as the transdermal patch or vaginal ring have the additional advantage of eliminating the need for daily compliance, as well as offering a different pharmacokinetic profile. ${ }^{15}$ Daily intake of oral combined hormonal contraceptives creates peaks and troughs in ethinyl estradiol concentrations, whereas the ring and patch deliver more constant levels. Exposure is lowest with the ring, while the patch is associated with the greatest overall exposure. ${ }^{15}$ Intermenstrual bleeding, amenorrhea, breast tenderness, abdominal bloating, headache and nausea are a few of the common side effects of combined oral contraceptives. The transdermal patch has similar side effects, though breast discomfort and dysmenorrhea are significantly more common. The most frequent side effects associated with the vaginal ring are headache, leukorrhea, vaginitis, weight gain and nausea. ${ }^{15}$

Despite the advantages, there are several reasons why combined hormonal contraceptives are not typically used in the puerperium. The safety and timing of contraceptive initiation during lactation are subject to debate. Studies of hormonal contraceptive agents with doses of ethinyl estradiol or mestranol of $50 \mathrm{mcg}$ or more have demonstrated a suppressive effect on lactation. Those with $35 \mathrm{mcg}$ or less, still have some suppressive effects, and low-dose combination oral contraceptives containing $0.03 \mathrm{mg}$ ethinyl estradiol and $0.15 \mathrm{mg}$ levonorgestrel in women who had been nursing for one month, had a small but significant decrease in lactation performance and in weight gain of their infants ${ }^{17}$ or cause maternal anxiety about milk supply. This slight inhibition of lactation induced by combined oral contraceptive agents may be sufficient enough to discourage women from continuing breastfeeding, particularly in those whose desire to nurse is marginal. ${ }^{17}$ On the other hand, a 2003 Cochrane review concluded that there was insufficient evidence to establish the effect of combined hormonal contraceptives, if any, on milk quality or quantity ${ }^{18}$ and a systematic review confirmed an inconsistent effect of combined oral contraceptives on breastfeeding duration and success, and found that infant outcomes were not affected. ${ }^{19}$

An update to the US MEC, specifically regarding use of contraceptive methods during the postpartum period, was published in 2011. ${ }^{11}$ These updated recommendations describe specific guidelines stating that all postpartum women should not use combined hormonal contraceptives during the first 21 days postpartum due to significant increased risk of venous thromboembolism (VTE) (category 4). During days 21-42, non-breastfeeding women with risk factors for VTE (e.g. prior VTE, recent cesarean delivery, or smoking), should not use these methods for the same reason of increased VTE risk (category 3 ). Without additional risk factors for VTE, use of combined 
hormonal contraceptive during days 2142 is category 2, thus acceptable. After 42 days postpartum, no exceptions apply and use of combined hormonal contraceptives for all non-breastfeeding women is category 1 . In breastfeeding postpartum women, from 21 days to < 30 , regardless of the presence of additional risk factors for VTE, use is category 3 . Without additional risk factors for VTE, use of combined hormonal contraceptive from day 30 forward, is category $2 .^{11}$ (see table 1 ) Since ovulation is unlikely in the first month after delivery, women can be provided with a prescription for combined hormonal contraception to begin at one month (30 days from delivery).

\section{Progestogen-only contraceptives (progestin-only oral contraceptive pills, injectables)}

Progestogen-only hormonal methods, including progestin-only pills and depot medroxyprogesterone acetate (DMPA) injections have long been recommended as an alternative to combined hormonal contraceptives in the postpartum period. They are safe for postpartum women, including women who are breastfeeding, and can be initiated immediately postpartum (categories 1 and 2) ${ }^{11}$ (see table 1). Because progesterone withdrawal may be the stimulus that initiates lactogenesis, administration of progestin-only methods shortly after delivery could theoretically inhibit or alter lactation, so some authors recommend waiting at least 3 days postpartum for administration, ${ }^{20}$ however data for this is lacking and the risk of repeat pregnancy may outweigh the theoretical risk of altered lactation.
In a recent review on the topic, studies examining the initiation of progestogenonly methods among postpartum women consistently concluded that there were no overall, adverse effects on measures of breastfeeding success, such as duration of breastfeeding or time to supplementation. ${ }^{21}$ Studies also, importantly, showed no consistent adverse effects on infant health outcomes such as growth, gross development, psychomotor development, milestones, and general health. ${ }^{21}$ DMPA is commonly administered to US women before they are discharged from the hospital and has been recommended immediately postpartum by some experts. ${ }^{22}$ There are limited studies specifically examining administration of DMPA prior to hospital discharge in breastfeeding women, although existing studies have not shown detrimental effects on breastfeeding, infant growth, or development. $^{21}$

Some of the disadvantages of progestogen-only methods include the strict regimen of compliance required by progestin-only pills, prolonged and frequent bleeding in the etonorgestrel implant (Nexplanon), irregular menstrual bleeding and prolonged anovulation after discontinuation of DMPA, as well as weight gain and loss of bone mineral density (most relevant for adolescents). ${ }^{14,23}$ Progestin-only pills should be avoided in Hispanic women with gestational diabetes who are breastfeeding, because of an increased risk for subsequent development of type II diabetes. ${ }^{17}$ Contraindications include women with unexplained uterine bleeding, known breast cancer, benign or malignant liver tumors, or acute liver disease. ${ }^{14}$ 
Table 1. US MEC guidelines for contraceptive use

\begin{tabular}{|c|c|c|c|c|c|c|}
\hline Condition & COC/Ring/Patch & $\begin{array}{l}\text { Progestin- } \\
\text { only pill }\end{array}$ & DMPA & Implants & $\begin{array}{l}\text { LNG- } \\
\text { releasing } \\
\text { IUC }\end{array}$ & $\begin{array}{l}\text { Copper- } \\
\text { containing } \\
\text { IUC }\end{array}$ \\
\hline \multicolumn{7}{|l|}{$\begin{array}{l}\text { Postpartum } \\
\text { (non-breast-feeding) }\end{array}$} \\
\hline$<21$ days & 4 & 1 & 1 & 1 & & \\
\hline \multicolumn{7}{|l|}{$21-42$ days } \\
\hline Risk factors & 3 & 1 & 1 & 1 & & \\
\hline None & 2 & 1 & 1 & 1 & & \\
\hline$>42$ days & 1 & 1 & 1 & 1 & & \\
\hline \multicolumn{7}{|l|}{$\begin{array}{l}\text { Postpartum } \\
\text { (breast-feeding\} }\end{array}$} \\
\hline$<21$ days & 4 & 2 & 2 & 2 & & \\
\hline \multicolumn{7}{|l|}{21 to $<30$} \\
\hline Risk factors & 3 & 2 & 2 & 2 & & \\
\hline None & 3 & 2 & 2 & 2 & & \\
\hline \multicolumn{7}{|l|}{$30-42$} \\
\hline Risk factors & 3 & 1 & 1 & 1 & & \\
\hline None & 2 & 1 & 1 & 1 & & \\
\hline$>42$ days & 2 & 1 & 1 & 1 & & \\
\hline \multicolumn{7}{|l|}{$\begin{array}{l}\text { Postpartum } \\
\text { (breast-feeding, non- } \\
\text { breastfeeding, } \\
\text { cesarean delivery) }\end{array}$} \\
\hline $\begin{array}{l}<10 \quad \min \text { after } \\
\text { placental delivery }\end{array}$ & & & & & 2 & 1 \\
\hline $\begin{array}{l}10 \text { min to }<4 \text { weeks } \\
\text { after placental } \\
\text { delivery }\end{array}$ & & & & & 2 & 2 \\
\hline$\geq 4$ weeks & & & & & 1 & 1 \\
\hline Peurperal sepsis & & & & & 4 & 4 \\
\hline
\end{tabular}

Abbreviations: COC (combined oral contraceptive), DMPA (depot medroxyprogesterone acetate injection), LNG (levonorgestrel), IUC (intrauterine contraceptive.

Key: 1 - no restriction; 2 - advantages generally outweigh theoretical risks; 3 - theoretical or proven risks usually outweigh the advantages; 4 - unacceptable health risk 
Long-acting reversible contraceptive methods (progestogen-only methods including subdermal implants and intrauterine contraceptives)

Intrauterine contraception (IUC) in the postpartum period warrants special consideration, especially given the push for long-acting reversible contraceptives. According to a recent American College of Obstetricians and Gynecologists committee opinion, the United States' high unintended pregnancy rate may be in part, due to a relatively low use of long-acting reversible contraceptive (LARC) methods. ${ }^{24}$ Despite an increase in use since 1995 (when $0.8 \%$ of US women chose intrauterine contraceptive), only $3.5 \%$ of all reproductive age women and $5.6 \%$ of contraceptive-using women use an intrauterine contraceptive device. ${ }^{3}$

IUCs, including the levonorgestrelreleasing IUC and copper-containing IUC, are highly effective in preventing pregnancy, with pregnancy rates less than 1 per 100 woman-years. $^{25}$ Excellent candidates include women who desire inter-pregnancy interval of more than 2 to 3 years, desire long-term contraception but prefer to avoid sterilization, breastfeeding women, women with side effects from hormonal contraception, and women with prior birth control failures, ${ }^{17}$ though all women who desire highly effective contraception should be considered candidates. In general, disadvantages include the uncommon side effects of uterine perforation, expulsion and discontinuation secondary to side effects, such as increased vaginal bleeding in copper-containing devices and decreased vaginal bleeding in progesterone-releasing. Some of the pertinent contraindications in the puerperium include postpartum endometritis and uterine anomalies. ${ }^{14,17}$ With appropriate counseling, the IUC may be used in women with a history of ectopic pregnancy or with risk factors for ectopic pregnancy. ${ }^{13}$

While traditionally inserted 4-8 weeks postpartum, ${ }^{14,26,27}$ there is much interest in the option of immediate post-placental insertion. Insertion of an IUC immediately after delivery is appealing for many reasons; the woman is known not to be pregnant, her motivation for contraception may be high, and for those women with limited access to medical care, hospitalization related to the delivery affords a unique opportunity to address the need for contraception. ${ }^{28}$ One US study showed that of 193 women who desired a postpartum IUC, $35 \%$ did not return for a postpartum visit and only $60 \%$ actually received an IUC. Seven $(3.6 \%)$ of these women actually became pregnant before they were able to receive an IUC. ${ }^{29}$ Other studies have described similar findings. ${ }^{28}$ Therefore, immediate postpartum insertion would certainly seem to improve utilization rates. In a small study investigating postpartum insertion immediately (within 10 minutes of placenta delivery), early (10 min to 48 hours postpartum), or interval ( $\geq 6$ weeks postpartum), there was no difference in utilization rates between groups at 3 and 6 months postpartum. $^{26}$ Another study echoed these results, finding that use of the levonorgestrel-releasing IUC at 6 months postpartum was not different between women who received postplacental or delayed insertion. ${ }^{30}$ These findings come despite the higher expulsion rates with post-placental 
insertion, which vary from $10-27 \%,{ }^{26,28,31}$ and even $38 \%$ in one study, ${ }^{10}$ compared with $1-6 \%$ at one year with interval insertion. ${ }^{26,30}$ With close clinical followup (2 weeks postpartum suggested by one author ${ }^{26}$ ) and early identification of expulsions so that reinsertion can occur, overall continuation/utilization rates at 3 and 6 months may not be impacted. ${ }^{26,30}$

A Cochrane review on the topic concluded that immediate post-partum insertion of IUCs appears safe and effective. ${ }^{28}$ According to guidelines by US MEC, IUCs, including the levonorgestrel-releasing IUD and copper-containing IUD, may be inserted postpartum, including immediately after delivery (categories 1 and 2) and are not associated with an increase in complications. ${ }^{11,13,30}$ The convenience of immediate postpartum insertion of a long-acting reversible contraception (LARC) reduces barriers to access, possibly outweighing the known disadvantage of an increased expulsion rate. $^{24}$

Studies reviewed by Truitt et al. did not find that IUCs interfere with lactation, ${ }^{18}$ though a more recent study investigated the impact on breastfeeding duration by post-placental or delayed levonorgestrel intrauterine device insertion. ${ }^{32}$ These authors found that more women in the delayed group compared with the postplacental group continued to breastfeed at 6-8 weeks, 3 months, and 6 months postpartum. $^{32}$ The difference was only significant at 6 months.

Approximately $14-35 \%$ of adolescent mothers become pregnant again within one year of delivery, despite intention to use contraception. ${ }^{33}$ We know from emerging evidence that increasing the use of contraceptive implants and intrauterine contraceptives (IUCs) could reduce repeat pregnancy among adolescent mothers. ${ }^{24}$ Typical use pregnancy rates are lower and continuation rates are higher for LARCs when compared to oral hormonal methods.

In a US study of adolescent mothers, initiation of the six-rod contraceptive implant (Norplant) was the factor most strongly associated with repeat pregnancy prevention in the first 2 postpartum years. ${ }^{34}$ Despite the unavailability of Norplant in the US, in a recent study investigating early initiation of the etonogestrel implant versus an intrauterine contraceptive, the implant was far more likely to be received prior to resumption of sexual activity than the IUC. ${ }^{33}$

\section{Lactational amenorrhea method}

Postpartum ovulation and return to fertility is delayed for breastfeeding women, to 8-10 weeks or more. ${ }^{14,16,17}$ Lactational amenorrhea can be used as an effective method of contraception provided the woman is exclusively breastfeeding (on demand, day and night more than 5 times per day, total suckling duration greater than 65 minutes, and at least 10 minutes per feed), ${ }^{35}$ has not resumed menses and is within six months of delivery. ${ }^{16,23,27}$ This method, when used properly, is at least $98 \%$ effective during the first 6 months postpartum. ${ }^{16,36} \quad$ Lactational amenorrhea becomes less effective after 6 months postpartum, or when menstrual bleeding resumes, or supplemental feedings are introduced. At which point another form of contraception must be initiated to 
reliably prevent pregnancy. ${ }^{16}$ Indeed, a recent World Health Organization (WHO) study on lactational amenorrhea revealed that cumulative pregnancy rates at 12 months were as high as $7.4 \%{ }^{23}$ Even in breastfeeding women whose amenorrhea extends beyond 6 months, there is an increased tendency for the first ovulation to precede the first menstruation; thus the contraceptive reliability of breastfeeding diminishes with time. ${ }^{12,14,27}$

Even women planning on using lactational amenorrhea for postpartum contraception may benefit from anticipatory guidance and/or provision of contraceptives. ${ }^{16} \quad$ One US study demonstrated that $8 \%$ of women who were planning on breastfeeding their newborns at the time of discharge from the hospital never initiated breastfeeding, and another $22 \%$ discontinued prior to the sixth postpartum week, putting them at risk of conception earlier than fully breastfeeding women. ${ }^{36}$ The success of this method is more likely to be achieved in highly motivated couples than among the general population. ${ }^{30}$

\section{Barrier contraception}

The use of barrier methods, including condoms, spermicides, and diaphragm/cap, have a category 1 distinction from the US MEC for use in all cases postpartum, with the one exception of the diaphragm/cervical cap, which cannot be used less than 6 weeks postpartum due to lack of complete uterine involution. ${ }^{13}$ For condoms in particular, advantages are familiarity with this method, as they are used for contraception by $10.2 \%$ of all women in the United States $(16.4 \%$ of women using some form of contraception), ${ }^{5}$ and protection against sexually transmitted infections. Condoms are often advised for postpartum women who wish to postpone a decision about contraceptive therapy or sterilization until the postpartum visit. ${ }^{17}$ With perfect and typical use, pregnancy rates with condoms are $2 \%$ and $15 \%$ respectively. ${ }^{25}$ Pregnancy rates for the other barrier methods are substantially higher. ${ }^{25}$ The diaphragm has the disadvantages of requiring fitting by a physician and re-fitting is required after delivery due to changes in the vagina and cervix. Additionally, weight alterations and deliveries might change the vaginal diameter. ${ }^{23}$ In breastfeeding women, low estrogen levels contribute to vaginal dryness and tightness, making proper fitting of a diaphragm more difficult. Proper size of the diaphragm should be determined at the 6 -week postpartum visit. ${ }^{17}$ The only side effects are vaginal wall irritation and an increased risk of urinary tract infections. ${ }^{23}$

\section{Natural family planning}

In women with regular cycles, for whom periods of abstinence are acceptable, natural family planning may be used ${ }^{17}$ but is generally considered less reliable than combined-hormonal or progestinonly methods, IUCs, condoms, or LAM. Pregnancy rates with perfect use vary between 1 to $9 \%{ }^{25}$ Because regular menses are required of this method, in breastfeeding women less than 6 weeks postpartum, both the symptom-based (basal body temp and cervical secretions) and calendar-based methods should not be used. Greater than 6 weeks postpartum and with the resumption of menses, both methods 
should be used with caution and may require additional counseling to ensure the woman is using the method correctly. When at least 3 postpartum menses have occurred and cycles are regular again, a calendar-based method can be used. $^{13}$ In non-breastfeeding women, neither fertility awareness based method should be used less than 4 weeks postpartum. Greater than 4 weeks postpartum, women may use symptom-based methods without restriction or caution. Calendar-based methods may be used as soon as they have completed three postpartum menses. Methods appropriate for the postpartum period should be offered before that time. ${ }^{13}$

\section{Sterilization}

Female sterilization is used by $27 \%$ of contraceptive-using women or $16.5 \%$ of all reproductive age women in the United States, ${ }^{5}$ and the puerperium is a convenient time for tubal ligation. There are no restrictions on the recommendations for sterilization postpartum, $^{13}$ and it can be performed at the time of cesarean section or up to 48 hours after delivery. ${ }^{17}$ However, a small proportion of women regret this decision $\quad(1 \%-26 \%$ from different studies, with higher rates of regret reported by women who were younger at sterilization, ${ }^{13}$ which must be considered while counseling patients and likely benefits from perinatal counseling). Unfortunately, only $50 \%$ of women who desire postpartum sterilization actually undergo the procedure and nearly one half of women with unfulfilled sterilization request become pregnant again within one year. ${ }^{37}$ Ensuring that sterilization is available in the puerperium is vital to helping reduce unintended pregnancy.

\section{Postpartum contraception education for patients; when to start and how to counsel?}

Many reasons contribute to the continued rate of unintended pregnancy; these include lack of patient education, ineffective contraceptive methods, inconsistent use of contraception, unplanned sexual activity, and contraceptive failure. ${ }^{38}$ While many of these factors are patient-dependent, contraceptive counseling is one in the purview of clinicians. $^{39}$ The postpartum period represents a unique opportunity to provide contraception counseling. These women have close contact with providers, allowing time to discuss the many contraceptive options. Additionally, prenatal care visits offer additional opportunities to provide patients with information about contraception after delivery. ${ }^{40}$ Contraceptive counseling is particularly important for women who have experienced an unwanted pregnancy and those at risk for repeat unintended pregnancy. ${ }^{39}$ For some, counseling during pregnancy may be the first time having received any education on contraception. ${ }^{39}$

A CDC report summarizing the results of the 2004-2006 Pregnancy Risk Assessment Monitoring System (PRAMS) survey, indicated that $88.0 \%$ of postpartum women at risk for unintended pregnancy (not pregnant and sexually active) reported current use of at least one contraceptive method 2-9 months postpartum. $61.7 \%$ reported using a method defined as highly effective (sterilization, vasectomy, shot, pill, ring, patch or intrauterine 
device), $20.0 \%$ used a method defined as moderately effective (condoms), and $6.4 \%$ used less effective methods (including diaphragm, cervical cap, sponge, rhythm or withdrawal). Women with no prenatal care had the lowest rate of use, at $76.4 \% .{ }^{41}$ Yet other reports from demographic and health surveys in 27 countries indicate that as many as $2 / 3$ of postpartum women had an unmet need for contraception. ${ }^{42}$

Contraceptive education is considered by many to be a standard component of postpartum care. ${ }^{43}$ Indeed, various studies have indicated that between 77 $82 \%$ of women receive antenatal counseling regarding postpartum contraception, ${ }^{38-40}$ though one small study showed that contraception was discussed antenatally with only $4 \%$ of women. ${ }^{44}$ Postpartum discussions are initiated in $68-87 \%$ of women. ${ }^{38,40}$ The effectiveness of counseling interventions in reducing unintended pregnancy and increasing postpartum contraceptive use, however, has been seldom examined. ${ }^{39,43}$

Of those studies investigating the topic, several have concluded that focused contraceptive counseling in the postpartum or antepartum period is effective ${ }^{45-47}$ yet others report no impact on contraceptive use following contraception counseling ${ }^{48}$ alone, versus educational leaflets, ${ }^{49}$ or a short-term increase in contraceptive use only. ${ }^{40} \mathrm{~A}$ systematic review (2010) of contraceptive counseling interventions taking place in the postpartum period, including both short-term and multiplecontact interventions, concluded that postpartum contraceptive education led to more contraception use and fewer unplanned pregnancies, though, was based on a limited number of studies. ${ }^{43}$ There is evidence to suggest that prenatal counseling may be especially beneficial in increasing contraceptive use among women with lower levels of education $^{45}$ or low-income women at high risk for repeat unintended pregnancy. ${ }^{47}$ Given that women with no prenatal care had the lowest rate of postpartum contraception use, at $76.4 \%$, these women might benefit from more consultation about postpartum contraceptive options. ${ }^{41}$

Several small studies have investigated the way in which postpartum contraception is approached in an attempt to determine which method may be most effective. ${ }^{38,46-48,50}$ For example, women who watched a video were less satisfied than those who had received counseling from a physician, though the video watchers were as likely to be satisfied as those who received a pamphlet. ${ }^{43}$ In a paper investigating patient satisfaction and the impact of written material about postpartum contraceptive decisions in 109 women, women in the intervention group were more likely to state that written material contributed to their ultimate choice in birth control. ${ }^{38}$ Additionally, those women receiving multi-component antepartum contraceptive counseling (consisting of counseling, a videotape and written material) about oral contraception as well as usual care were more likely to remain not pregnant at their 12 month follow-up, compared to those who received usual care only. ${ }^{47} \mathrm{~A}$ 2008 randomized investigation found that women who were received postpartum contraception educational leaflets and 20 minute verbal counseling sessions were more likely to have started contraception $(56.9 \%$ versus 
$6.3 \%$ by the time of the postpartum follow-up visit, and were more likely to have chosen an effective method (i.e. oral hormonal contraceptive), compared to those who had not received the educational intervention. ${ }^{46}$

Others have attempted to identify the ideal timing for postpartum contraception counseling, with one qualitative study concluding that counseling should take place throughout the antenatal care process via thorough, frequent and provider-initiated discussions using multiple teaching modalities. Clearly, more work is needed to identify the optimal timing, method and content of effective perinatal contraceptive counseling that results in reduced unintended pregnancy rates, sustainable knowledge and pregnancy prevention behaviors. ${ }^{39}$

\section{Conclusion}

This review highlights the importance of utilizing the postpartum period to initiate contraceptive use among reproductive aged women, in order to decrease the risk of unintended pregnancy. Ideally, counseling will begin early on in the antenatal period and include providerinitiated discussions and a variety of teaching modalities. With a little time and effort on the part of the physician, we can help patients decide on an effective and appropriate method of contraception.

Postpartum tubal ligation is safe and easy to perform.

LARC options such as the etonogestrel implant and intrauterine devices may be inserted prior to discharge and may be safely used in breastfeeding women.
Combined hormonal methods such as the vaginal ring, patch or OCPs should not be used less than 21 days postpartum. However, prescriptions can be given prior to discharge for initiation of these methods after 30 days postpartum.

Progestin-only pills are a good option for women desiring an oral method and are appropriate for breastfeeding women.

\section{References}

1. Mosher WD, Jones J. Use of contraception in the United States: 1982-2008. Vital Health Stat 23. 2010 Aug;(29):1-44. PubMed PMID: 20939159.

2. Mishell Jr. DR. Chapter 14. Family Planning: Contraception, Sterilization, and Pregnancy Termination. In: Katz VL, Lentz GM, Lobo RA, Gershenson DM, eds. Comprehensive Gynecology. 5th ed. Philadelphia: Mosby; 2007.

3. Ventura SJ, Curtin SC, Abma JC, Henshaw SK. Estimated pregnancy rates and rates of pregnancy outcomes for the United States, 1990-2008. Natl Vital Stat Rep. 2012 Jun 20;60(7):1-21. PubMed PMID: 22970648.

4. Mosher WD, Jones J, Abma JC. Intended and unintended births in the United States: 1982-2010. Natl Health Stat Report. 2012 Jul 24;(55):1-28. PubMed PMID: 23115878.

5. Jones J, Mosher W, and Daniels K. Current Contraceptive Use in the United States, 2006-2010, and Changes in Patterns of Use since 1995. National health statistics reports; no. 60. Hyattsville, MD: National Center for Health Statistics. 2012. http://www.cdc.gov/nchs/data/nhsr/nhsr 060.pdf 
6. Gipson JD, Koenig MA, Hindin MJ. The effects of unintended pregnancy on infant, child, and parental health: a review of the literature. Stud Fam Plann. 2008 Mar;39(1):18-38. Review. PubMed PMID: 18540521 . DOI: $10.1111 / \mathrm{j} .1728-$ 4465.2008.00148.x

7. Zhu BP, Rolfs RT, Nangle BE, Horan JM. Effect of the interval between pregnancies on perinatal outcomes. $\mathrm{N}$ Engl J Med. 1999 Feb 25;340(8):58994. PubMed PMID: 10029642. http://dx.doi.org/10.1056/NEJM1999022 53400801

8. Grisaru-Granovsky S, Gordon ES, Haklai Z, Samueloff A, Schimmel MM. Effect of interpregnancy interval on adverse perinatal outcomes--a national study. Contraception. 2009 Dec;80(6):512-8. doi: 10.1016/j.contraception.2009.06.006. Epub 2009 Jul 22. PubMed PMID: 19913144.

9. Smith GC, Pell JP, Dobbie R. Interpregnancy interval and risk of preterm birth and neonatal death: retrospective cohort study. BMJ. 2003 Aug 9;327(7410):313. http://dx.doi.org/10.1136/bmj.327.7410.3 13 Erratum in: BMJ. 2003 Oct 11;327(7419):851. PubMed PMID: 12907483.

http://dx.doi.org/10.1136/bmj.327.7419.8 51

10. Stuart GS, Bryant AG, O'Neill E, Doherty IA. Feasibility of postpartum placement of the levonorgestrel intrauterine system more than $6 \mathrm{~h}$ after vaginal birth. Contraception. 2012 Apr;85(4):359-62. doi: 10.1016/j.contraception.2011.08.005. Epub 2011 Sep 28. PubMed PMID: 22067759.
11. Centers for Disease Control and Prevention (CDC). Update to CDC's U.S. Medical Eligibility Criteria for Contraceptive Use, 2010: revised recommendations for the use of contraceptive methods during the postpartum period. MMWR Morb Mortal Wkly Rep. 2011 Jul 8;60(26):878-83. PubMed PMID: 21734635.

12. Jackson E, Glasier A. Return of ovulation and menses in postpartum nonlactating women: a systematic review. Obstet Gynecol. 2011 Mar;117(3):657-62. doi: 10.1097/AOG.0b013e31820ce18c. PubMed

13. Centers for Disease Control and Prevention (CDC). U S. Medical Eligibility Criteria for Contraceptive Use, 2010. MMWR Recomm Rep. 2010 Jun 18;59(RR-4):1-86. PubMed PMID: 20559203.PMID: 21343770.

14. Cunningham FG, Leveno KJ, Bloom SL, Hauth JC, Rouse DJ, Spong CY. Chapter 32. Contraception. In: Cunningham FG, Leveno KJ, Bloom SL, Hauth JC, Rouse DJ, Spong CY, eds. Williams Obstetrics. 23rd ed. New York: McGraw-Hill; 2010.

15. Bitzer J, Simon JA. Current issues and available options in combined hormonal contraception. Contraception. 2011 Oct;84(4):342-56. doi: 10.1016/j.contraception.2011.02.013.

Epub 2011 Apr 27. PubMed PMID: 21920188.

16. Jackson E. Controversies in postpartum contraception: when is it safe to start oral contraceptives after childbirth? Thromb Res. 2011 Feb;127 Suppl 3:S35-9. doi: 10.1016/S00493848(11)70010-X. PubMed PMID: 21262436.

17. Katz VL. Chapter 21. Postpartum Care. In: Gabbe SG, Niebyl JR, Simpson JL, eds. Obstetrics: Normal and Problem Pregnancies. 5th ed. Philadelphia: Churchill Livingstone; 2007. 
18. Truitt ST, Fraser AB, Grimes DA, Gallo MF, Schulz KF. Combined hormonal versus nonhormonal versus progestin-only contraception in lactation. Cochrane Database Syst Rev. 2003;(2):CD003988. PubMed PMID: 12804497.

DOI: 10.1002/14651858.CD003988

19. Kapp N, Curtis KM. Combined oral contraceptive use among breastfeeding women: a systematic review. Contraception. $2010 \mathrm{Jul} ; 82(1): 10-6$. doi: 10.1016/j.contraception.2010.02.001.

Epub 2010 Mar 9. PubMed PMID: 20682139.

20. Kennedy KI, Short RV, Tully MR. Premature introduction of progestin-only contraceptive methods during lactation. Contraception. 1997 Jun;55(6):347-50. PubMed PMID: 9262929. http://dx.doi.org/10.1016/S00107824(97)00042-5

21. Kapp N, Curtis K, Nanda K. Progestogen-only contraceptive use among breastfeeding women: a systematic review. Contraception. 2010 Jul;82(1):17-37. 10.1016/j.contraception.2010.02.002. Epub 2010 Mar 29. PubMed PMID: 20682140.

22. Speroff L, Mishell DR Jr. The postpartum visit: it's time for a change in order to optimally initiate contraception. Contraception. 2008 Aug;78(2):90-8. doi:

10.1016/j.contraception.2008.04.005.

Epub 2008 Jun 12. PubMed PMID: 18672108.

23. Burkman RT. Chapter 36. Contraception \& Family Planning. In: DeCherney $\mathrm{AH}$, Nathan L, eds. CURRENT Diagnosis \& Treatment Obstetrics \& Gynecology. 10th ed. New York: McGraw-Hill; 2007.
24. American College of Obstetricians and Gynecologists Committee on Gynecologic Practice; Long-Acting Reversible Contraception Working Group. ACOG Committee Opinion no. 450: Increasing use of contraceptive implants and intrauterine devices to reduce unintended pregnancy. Obstet Gynecol. 2009 Dec;114(6):1434-8. doi: 10.1097/AOG.0b013e3181c6f965.

PubMed PMID: 20134301.

25. Trussell J. Contraceptive failure in the United States. Contraception. 2004 Aug;70(2):89-96. PubMed PMID: 15288211.

26. Dahlke JD, Terpstra ER, Ramseyer AM, Busch JM, Rieg T, Magann EF. Postpartum insertion of levonorgestrel-intrauterine system at three time periods: a prospective randomized pilot study. Contraception. 2011 Sep;84(3):244-8. doi: 10.1016/j.contraception.2011.01.007. Epub 2011 Feb 24. PubMed PMID: 21843688.

27. Evans A. Postpartum contraception. Women's Health Medicine. 2005;2(5):23-26.

http://dx.doi.org/10.1383/wohm.2005.2.5 .23

28. Grimes D, Schulz K, van Vliet $H$, Stanwood N. Immediate post-partum insertion of intrauterine devices: a Cochrane review. Hum Reprod. 2002 Mar;17(3):549-54. PubMed PMID: 11870101. http://dx.doi.org/10.1093/humrep/17.3.5 49

29. Ogburn JA, Espey E, Stonehocker J. Barriers to intrauterine device insertion in postpartum women. Contraception. 2005 Dec;72(6):426-9. Epub 2005 Aug 9. PubMed PMID: 16307964. http://dx.doi.org/10.1016/j.contraception. 2005.05.016 
30. Chen BA, Reeves MF, Hayes JL, Hohmann HL, Perriera LK, Creinin MD. Postplacental or delayed insertion of the levonorgestrel intrauterine device after vaginal delivery: a randomized controlled trial. Obstet Gynecol. 2010 Nov;116(5):1079-87. doi: 10.1097/AOG.0b013e3181f73fac.

PubMed PMID: 20966692.

31. Hayes JL, Cwiak C, Goedken P, Zieman M. A pilot clinical trial of ultrasound-guided postplacental insertion of a levonorgestrel intrauterine device. Contraception. 2007 Oct;76(4):292-6. Epub 2007 Aug 6. PubMed PMID: 17900440. http://dx.doi.org/10.1016/j.contraception. 2007.06.003

32. Chen BA, Reeves MF, Creinin MD, Schwarz EB. Postplacental or delayed levonorgestrel intrauterine device insertion and breast-feeding duration. Contraception. 2011 Nov;84(5):499-504. doi:

10.1016/j.contraception.2011.01.022.

Epub 2011 Apr 16. PubMed PMID: 22018124.

33. Tocce K, Sheeder J, Python J, Teal SB. Long acting reversible contraception in postpartum adolescents: early initiation of etonogestrel implant is superior to IUDs in the outpatient setting. J Pediatr Adolesc Gynecol. 2012 Feb;25(1):59-63. doi: 10.1016/j.jpag.2011.09.003. Epub 2011 Nov 3. PubMed PMID: 22051792.

34. Stevens-Simon C, Kelly L, Kulick R. A village would be nice but...it takes a long-acting contraceptive to prevent repeat adolescent pregnancies. Am J Prev Med. 2001 Jul;21(1):60-5. PubMed PMID: 11418259 http://dx.doi.org/10.1016/S07493797(01)00316-6
35. McNeilly AS, Glasier AF, Howie PW, Houston MJ, Cook A, Boyle H. Fertility after childbirth: pregnancy associated with breast feeding. Clin Endocrinol (Oxf). 1983 Aug;19(2):167-73. PubMed PMID: 6883735. http://dx.doi.org/10.1111/j.13652265.1983.tb02978.x

36. Halderman LD, Nelson AL. Impact of early postpartum administration of progestin-only hormonal contraceptives compared with nonhormonal contraceptives on short-term breastfeeding patterns. Am J Obstet Gynecol. 2002 Jun;186(6):1250-6; discussion 1256-8. PubMed PMID: 12066106. http://dx.doi.org/10.1067/mob.2002.123 738

37. Committee on Health Care for Underserved Women. Committee opinion no. 530: access to postpartum sterilization. Obstet Gynecol. 2012 Jul;120(1):212-5. doi: 10.1097/AOG.0b013e318262e354.

PubMed PMID: 22914423.

38. Johnson LK, Edelman A, Jensen J. Patient satisfaction and the impact of written material about postpartum contraceptive decisions. Am J Obstet Gynecol. 2003 May;188(5):1202-4. PubMed PMID: 12748478. http://dx.doi.org/10.1067/mob.2003.308

39. Yee L, Simon M. Urban minority women's perceptions of and preferences for postpartum contraceptive counseling. J Midwifery Womens Health. 2011 Jan-Feb;56(1):54-60. doi: 10.1111/j.1542-2011.2010.00012.x. PubMed PMID: 21323851.

40. Glazer AB, Wolf A, Gorby N. Postpartum contraception: needs vs. reality. Contraception. 2011 Mar;83(3):238-41. doi: 10.1016/j.contraception.2010.07.002. Epub 2010 Aug 7. PubMed PMID: 21310285. 
41. Centers for Disease Control and Prevention (CDC). Contraceptive use among postpartum women - 12 states and New York City, 2004-2006. MMWR Morb Mortal Wkly Rep. 2009 Aug 7;58(30):821-6. PubMed PMID: 19661855.

42. Ross J, Winfrey W. Contraceptive use, intention to use and unmet need during the extended postpartum period. Int Fam Plan Perspect 2001;27:20-7. http://dx.doi.org/10.2307/2673801

43. Lopez LM, Hiller JE, Grimes DA. Postpartum education for contraception: a systematic review. Obstet Gynecol Surv. 2010 May;65(5):325-31. doi: 10.1097/OGX.0b013e3181e57127.

Review. PubMed PMID: 20591202.

44. Glasier AF, Logan J, McGlew TJ. Who gives advice about postpartum contraception? Contraception. 1996 Apr;53(4):217-20. PubMed PMID: 8706439.

http://dx.doi.org/10.1016/00107824(96)00040-6

45. Hernandez LE, Sappenfield WM, Goodman D, Pooler J. Is effective contraceptive use conceived prenatally in Florida? The association between prenatal contraceptive counseling and postpartum contraceptive use. Matern Child Health J. 2012 Feb;16(2):423-9. doi: $\quad$ 10.1007/s10995-010-0738-9. PubMed PMID: 21197562.
46. Saeed GA, Fakhar S, Rahim F, Tabassum $S$. Change in trend of contraceptive uptake--effect of educational leaflets and counseling. Contraception. 2008 May;77(5):377-81. doi:

10.1016/j.contraception.2008.01.011.

Epub 2008 Mar 19. PubMed PMID: 18402856.

47. Gilliam M, Knight S, McCarthy M Jr. Success with oral contraceptives: a pilot study. Contraception. 2004 May;69(5):413-8. PubMed PMID: 15105065.

http://dx.doi.org/10.1016/j.contraception. 2003.12.006

48. Engin-Ustün $\mathrm{Y}$, Ustün $\mathrm{Y}$, Cetin $\mathrm{F}$, Meydanli MM, Kafkasli A, Sezgin B. Effect of postpartum counseling on postpartum contraceptive use. Arch Gynecol Obstet. 2007 Jun;275(6):42932. Epub 2006 Nov 29. PubMed PMID: 17136370.

http://dx.doi.org/10.1007/s00404-0060287-z

49. Akman $M$, Tüzün $S$, Uzuner $A$, Başgul A, Kavak Z. The influence of prenatal counselling on postpartum contraceptive choice. J Int Med Res. 2010 JulAug;38(4):1243-9. PubMed PMID: 20925996.

http://dx.doi.org/10.1177/147323001003 800405

50. Proctor A, Jenkins TR, Loeb T, Elliot $M$, Ryan A. Patient satisfaction with 3 methods of postpartum contraceptive counseling: a randomized, prospective trial. J Reprod Med. 2006 May;51(5):377-82. PubMed PMID: 16779983. 